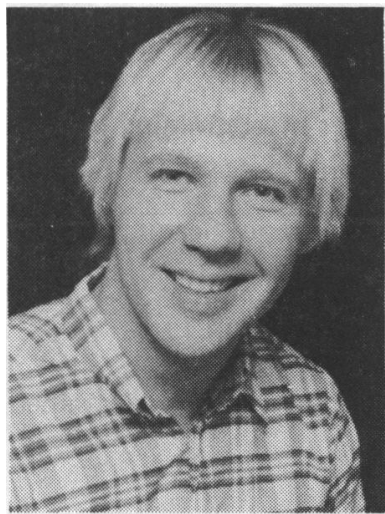

R. Cetti

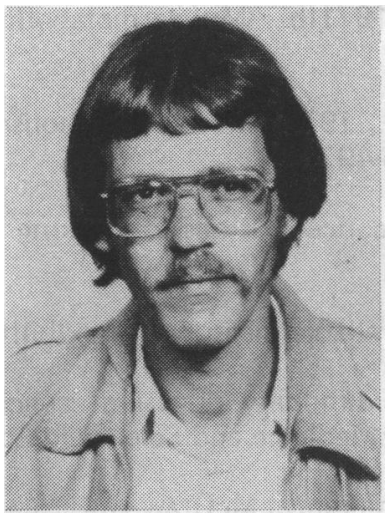

S. E. Christensen

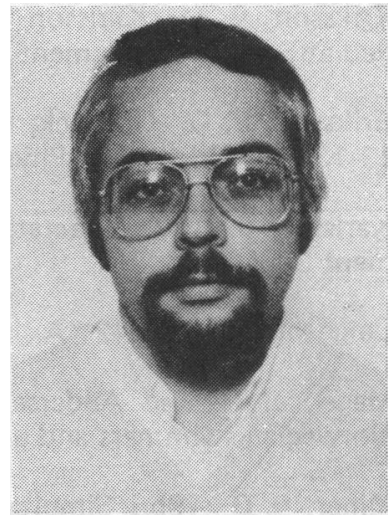

M. T. Corfitsen

\title{
RUPTURED FIBULAR ANKLE LIGAMENT: PLASTER OR PLITON BRACE?
}

R. CETTI, MD, S.-E. CHRISTENSEN, MD and M. T. CORFITZEN, MD

Department of Orthopaedic Surgery, Frederiksberg University Hospital, Copenhagen, Denmark

\section{ABSTRACT}

A prospective randomised study was performed in order to compare plaster cast with Pliton-80 cast brace with a mobile plastic shoe insert in the treatment of ruptured fibular ankle ligaments. The two treatment groups consisted of 65 patients in each and all were participating in the follow-up sixth months after the accident. There were no? statistically significant differences in the overall results between the two treatment groups.

Because 1) the mobile Pliton- 80 bandage subjectively is more acceptable to the patients and -2 ) the disability time in the Pliton-80 group was considerably shorter than in the plaster group - it was concluded that the mobile Pliton-80 bandage can be recommended as the treatment of ruptures of the fibular ankle ligaments.

\section{INTRODUCTION}

Acute inversion injuries of the ankle commonly result in rupture of the fibular ankle ligaments. This trauma to the ankle joint is one of the most common types of injury to the musculo-skeletal system and is seen typically in young athletes.

Most studies on this subject have tried to elucidate whether the treatment of choice should be operation or plaster cast. Most authors recommend conservative treatment and only resort to operation in selected cases where the trauma has resulted in severe damage to the ligaments (Adler, 1976; Saunders, 1980).

\section{Correspondence and reprint requests to:}

René Cetti, MD

Edisonsvej 12,2.tv, 1856, V

Denmark
Recent publications have not only dealt with problems concerning conservative or operative treatment but have also described alternative forms of conservative treatment (Cetti, 1981; Clark et al, 1965; Niedermann et al, 1981; Van Moppes and Van den Hoogenband, 1982). Freeman (1965) and Cetti (1981) stressed that early mobilisation enhances muscular stimulation and proprioception, thereby adding to the stability of the ankle joint. Van Moppes and Van den Hoogenband (1982) concluded that early mobilisation with support of a specific tape bandage (Couman's bandage) for 6 weeks was superior to both operative and plaster treatment.

The purpose of the present study is to describe the results of a prospective randomised comparison between a thermoplastic bandage with a mobile shoe insert and a conventional below-knee walking plaster in the treatment of ruptured fibular ankle ligaments. 


\section{MATERIAL AND METHODS}

The material comprises all patients who came to the emergency department of Frederiksberg University Hospital of Copenhagen during the period from July 1981 to July 1982 with acute sprain of the ankle. Of a total of 24,396 patients, 624 were treated for sprained ankles. Of these, 130 patients had positive stress radiograms indicating rupture of the fibular ankle ligaments and were assigned randomly to treatment either by a below-knee walking plaster of by a Pliton- 80 cast brace with a mobile plastic shoe insert, both for 6 weeks. In each group 65 patients were treated.

There were 69 men and 61 women. The mean age was 26 years, range $13-76$ years (Fig. 1). Sixty-five ruptures were in the left ankle, and 65 in the right.

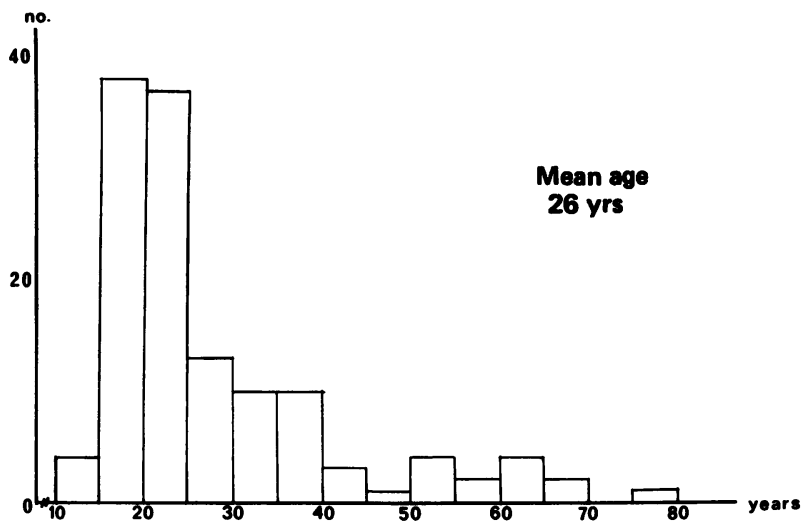

Fig. 1: Age distribution of patients with ruptures of the lateral ligament of the ankle. $\delta N=69$ \& $N=61$.

Most patients (42\%) sustained their sprains while engaged in sport. The remaining $58 \%$ were from a wide variety of domestic, industrial and other causes.

\section{DIAGNOSIS}

Rupture of the ligaments was confirmed on stress radiograms taken after application of local infiltration anaesthesia at the site of injury. A difference in talar tilt of $6^{\circ}$ or more and/or a difference of $3 \mathrm{~mm}$ or more in the anterior drawer test between the injured (I) and uninjured (U) ankle was considered diagnostic (Fig. 2) (Brand, 1977; Evans and Frenyo, 1979; Freeman, 1965).

\section{TREATMENT}

Half of the patients, 65 in number were treated by below-knee walking plaster for 6 weeks and 65 were treated by the mobile Pliton- 80 bandage which allows limited movement in the ankle joint (Fig. 3). The plastic shoe insert has a construction allowing only certain movements of the ankle joint (Fig. 4). Figure 5 shows
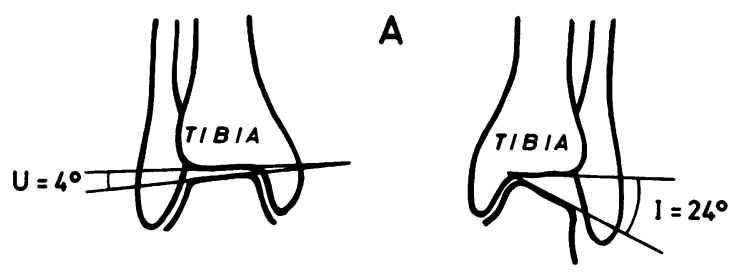

$(I-U)^{\circ}=(24-4)^{\circ}=20^{\circ} \geqslant 6^{\circ}$

Fig. 2: Stress radiography: Criteria of talar tilt and anterior drawer sign regarded as diagnostic of lateral ligament rupture.

$U$ (left side of fig. $)=$ uninjured.

I (right side of fig. $)=$ complete rupture .

the mobility with and without support of the Pliton-80 bandage. In a patient without sprain following movements were measured without/with the bandage: Dorsiflexion $25^{\circ} / 20^{\circ}$, plantar flexion $50^{\circ} / 20^{\circ}$, inversion $40^{\circ} / 10^{\circ}$.

\section{FOLLOW-UP}

All patients returned for clinical and radiological reexamination 2 months after the injury. Further clinical re-examination and interview including questions concerning their personal opinion of the treatment and end-result took place 6 months after the accident.

\section{STATISTICS}

The Mann-Whitney U-test and Chi-square test with various degrees of freedom were used to control the variables of the 2 groups and the results of the investigation. The significance level was pre-selected as $95 \%$. Insignificant results are marked NS, while the exact value of $p$ is indicated in all cases of significance.

\section{RESULTS}

Before $X$-ray examination all patients had a provisional diagnosis of injury to the fibular ligaments made on 


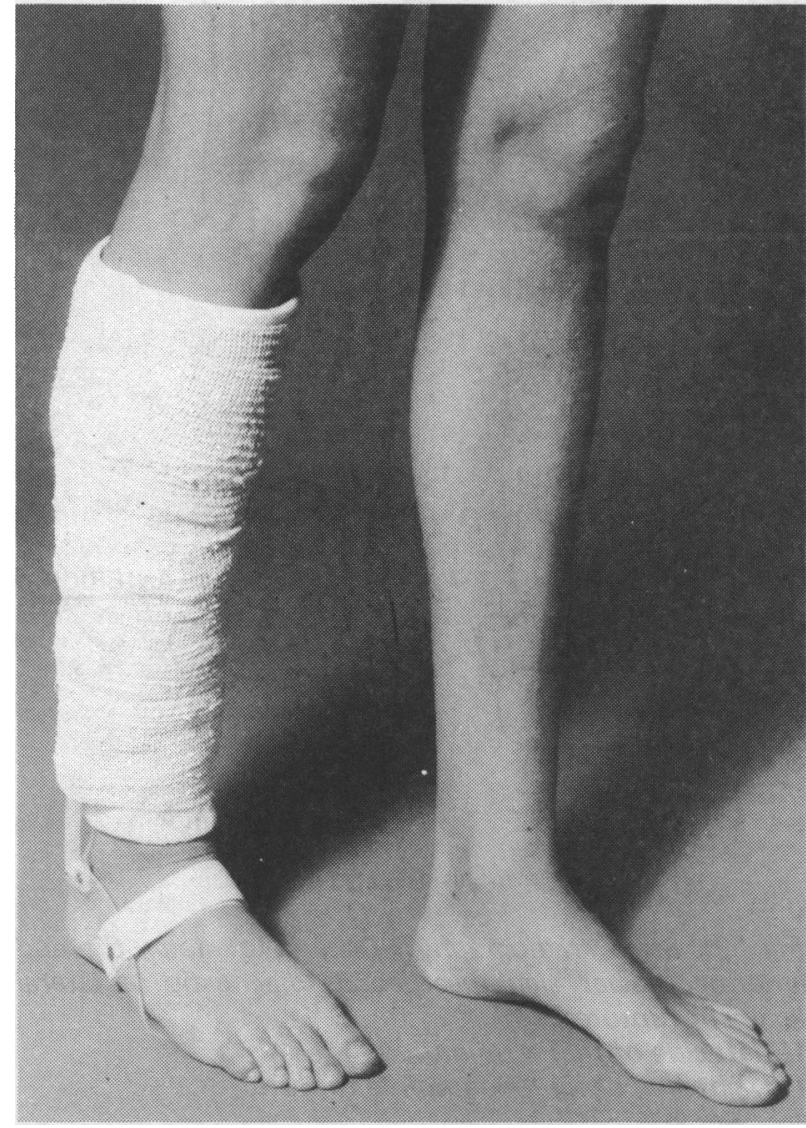

Fig. 3: The Pliton-80 bandage.

clinical grounds. Table I shows the extent to which the sport performers had resumed their former sport at the 6 months follow-up. Two patients in the Pliton80 group had reduced their activity because of subjective functional instability and intermittent pain in the ankle joint respectively. In the plaster group 3 had reduced their activity and one had stopped because of functional instability, while intermittent pain caused one to reduce activity and one to stop.

The patient's own assessment conceming the two was graded into heavy, fairly heavy and light work, defined as 1) walking with strain, 2) walking without strain and 3) mainly sedentary work. Table II sets out the sick-leave period related to the severity of the work.

The patients' own assessment concerning the two treatments is seen in Table III. Forty patients (62\%) had the plaster bandage repaired during the treatment, compared with $5(8 \%)$ in the Pliton-80 group. Table IV shows the patient's assessments of the treatment as a whole including the end results.

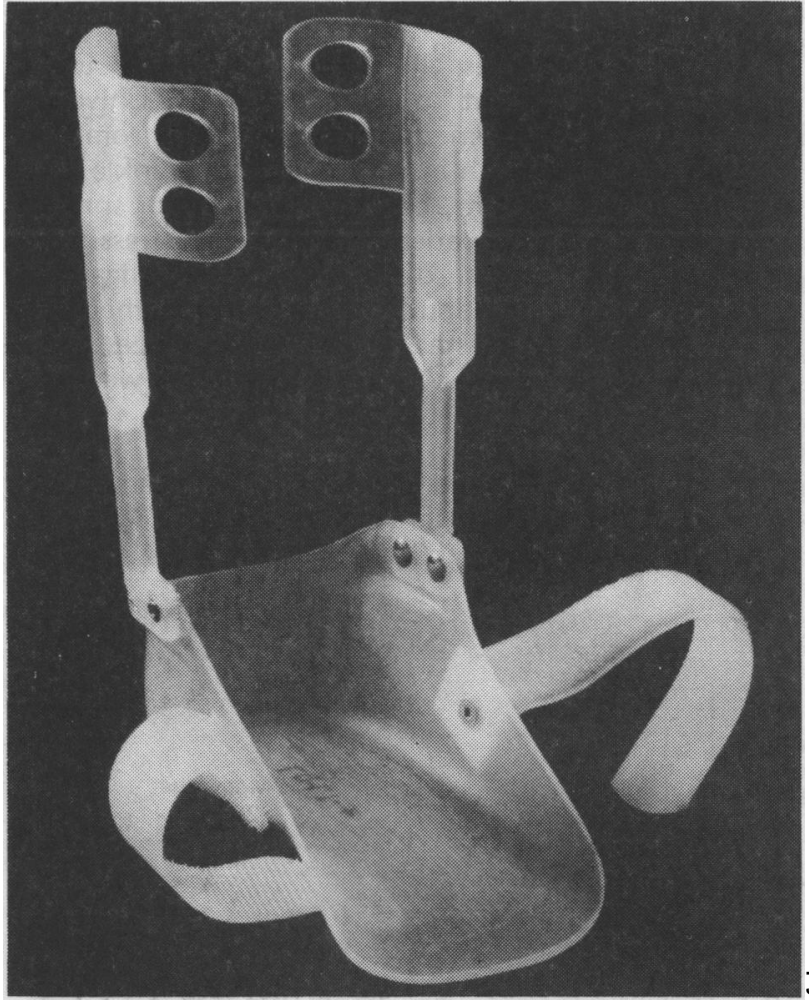

Fig. 4: The plastic shoe insert.

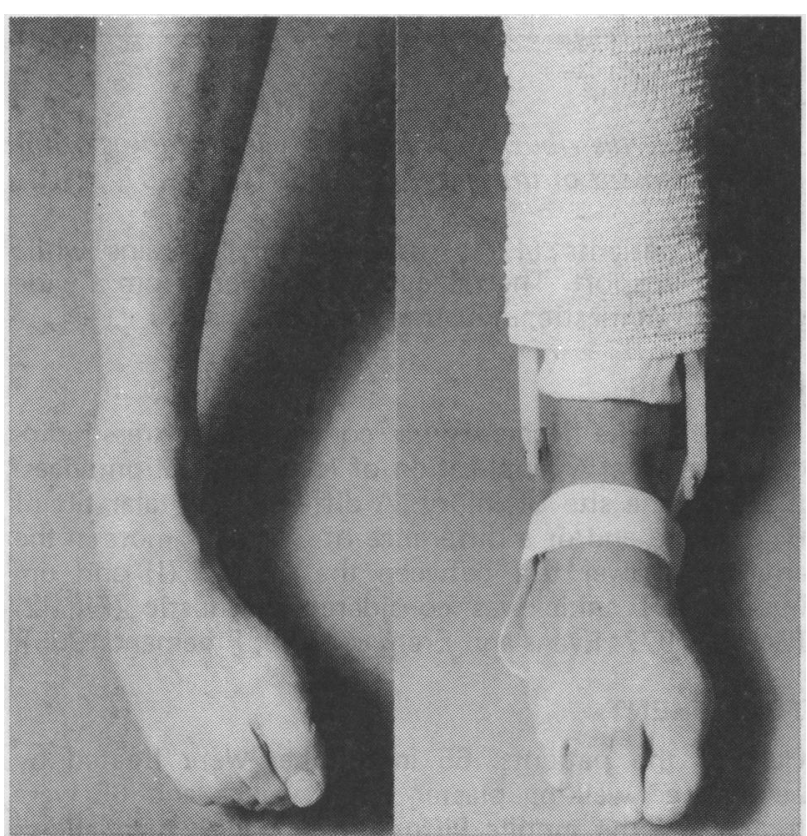

Fig. 5: Limits of inversion without and with the Pliton bandage.

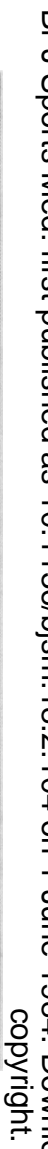


TABLE I

Sport activity 6 months after the injury in 80 sport performers with injured fibular ankle ligaments

$\begin{array}{ccc}\text { Sport activity } & \text { Plaster } & \text { Pliton® } \\ \text { same extent } & 34 & 38 \\ \text { lesser extent } & 4 & 2 \\ \text { stopped } & 2 & 0 \\ \text { Total } & 40 & 40\end{array}$

\section{TABLE II}

Correlation between sick-leave and severity of employment in 130 patients with injured fibular ankle ligaments (Chi-square significant, $p<0.05$ )

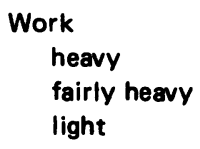

Work

heavy

fairly heavy

light

Mean (days)

\begin{abstract}
Plaster
43.1 days

44.2 days

31.5 days
\end{abstract}

37.5 (range 2-63)

\section{TABLE III}

Assessment concerning the bandages in 130 patients with injured fibular ankle ligaments (Chi-square non-significant, $p<0.2$ )

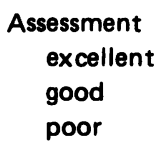

Total

Plaster
37
21
7

65

\section{TABLE IV}

Assessment concerning the treatment, including the end result in 130 patients with injured fibular ankle ligaments (Chi-square significant, $p<0.025$ )
Total

\author{
Assessment \\ excellent \\ good \\ poor
}

Pliton $®$
56
7
2

65
At follow-up 8 weeks after the injury a "modified Romberg's test" was employed. The patient was asked to stand first on the uninjured foot with the eyes open and then closed, and then to repeat this sequence on the injured side. The test was positive when the patient felt more unstable while standing on the injured foot. The test was instituted in order to evaluate to what extent it could be related to functional instability (FI), defined as a feeling of insecurity in the ankle joint and tendency for the foot to "give way". Table V shows the result of $\frac{c}{8}$ the follow-up 8 and 24 weeks after the accident. Of the 13 patients with FI 8 weeks after the injury 10 had के positive "modified Romberg's test". The corresponding numbers at 6 months were 18 and 15. The specificity ( $\left.\frac{\text { true positive }}{\text { true + false positive }}\right)$ of the "modified Romberg's test" for FI 8 weeks after the accident was estimated to 0.22 . At the same time the sensitivity $\left(\frac{\text { true negative }}{\text { true }+ \text { false negative }}\right)$ was 0.95 . At 6 months follow-up the specificity was 0.6 and the sensitivity 0.97 (Armitage, 1977).

\section{TABLE V}

The results of the follow-up examination 8 weeks and 24 weeks after the injury in 130 patients with injured fibular ankle ligaments

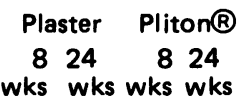

$\begin{array}{rl}\text { Chi-square } \\ 8 & 24 \\ \text { wks } & \text { wks }\end{array}$

New sprain after removal of bandage

Functional instability

$3 / 12 \quad 2 / 6$

$9 / 12 \quad 4 / 6$

NS/NS

Positive "modified

Romberg's test"

Intermittent pain and swelling of ankle

$30 / 17$

16/ 8

$p<0.025$ /NS

$24 / 8 \quad 6 / 4 \quad p<0.0005 /$ NS

Clinical examination

\begin{tabular}{|c|c|c|c|}
\hline Abnormal gait & $13 / 3$ & $0 / 0$ & \\
\hline Painful ankle movements & $8 / 3$ & $0 / 0$ & \\
\hline Diminished ankle motion & $10 / 3$ & $0 / 0$ & \\
\hline Positive talar tilt test & $2 / 4$ & $1 / 3$ & \\
\hline Positive drawer test & $8 / 4$ & $2 / 4$ & \\
\hline Swelling of the ankle & $25 / 6$ & $10 / 2$ & $p<0.01 \quad / N S$ \\
\hline $\begin{array}{l}\text { Tenderness of the } \\
\text { injured ligaments }\end{array}$ & $24 / 15$ & $11 / 7$ & $p<0.025 / N S$ \\
\hline \multicolumn{4}{|l|}{ Total } \\
\hline $\begin{array}{l}\text { Residual signs and } \\
\text { symptoms }\end{array}$ & $90 / 38$ & $24 / 16$ & \\
\hline
\end{tabular}

\section{DISCUSSION}

Broström (1966) stated that although surgical treatment of ruptured fibular ankle ligaments gave the best long term results, it could not be recommended for routine treatment because of 1) The risk of postoperative infection and osteoarthritis, 2) Discomfort from the scar i.e. altered sensibility and neuroma, and 3) because secondary surgical reconstruction, if necessary, can be performed with good results. He also pointed out that residual symptoms after conservative treatment usually are mild, and that the duration of sick-leave after operation is considerably longer than after conservative treatment. Recent studies have verified that conservative 
treatment with early mobilisation still is preferable (Cetti, 1981; Niedermann et al, 1981; Van Moppes and Van den Hoogenband, 1982).

The present study confirms that diagnosis of ligamentous ankle injuries most often requires stress radiograms (Glasgow et al, 1980). The ligaments and the capsule of the ankle joint contain Pacini and Golgi types of nerve receptors and Ruffini end organs. Some of these proprioceptors are specialised to respond to movement of the joint, and impulses from these nerves are extremely important for the co-ordination of movement and for information concerning joint position. The ability to balance on one foot with the eyes closed is mainly based on information originating in these receptors and consequently the "modified Romberg's test" should be a monitor for an eventual proprioceptive nerve lesion. We believe that this test is positive if there is such a lesion and/or if the triceps surae muscle has marked weakening. The results of the 6 months followup shows that the test is useful to monitor patients having functional instability, but further investigations are necessary to elucidate whether the patients with $\mathrm{FI}$ are suffering from proprioceptive nerve damage, have a weak triceps surae muscle or a laxity of the ligaments/capsule which may be difficult to diagnose.

It has been shown earlier that $\mathrm{FI}$ is not significantly correlated with mechanical instability in the ankle joint (Cetti, 1981; Freeman, 1965) although it has been stated that $\mathrm{FI}$ is due to mechanical instability (Broström, 1966; Weber and Hupfauer, 1969). In our opinion mechanical instability is not the main cause for functional instability because the patients with FI seldom sustain real distorsion but only have a feeling of insecurity in the ankle joint.

Among sportsmen it is of the utmost importance to undergo a treatment which leads to a quick return to sport at the same level as before the accident. Plaster immobilisation and surgical treatment both make a large break in the training programme, while patients treated with the mobile Pliton-80 bandage return to sport quickly. Functional instability is the most common and most serious residual symptom following rupture of the ankle ligaments. Twelve patients in the plaster group had FI compared to 6 in the Pliton-80 group. Despite the apparently favourable results in the Pliton- 80 group this difference is not statistically significant. The result is in accordance with other publications although the methods and presumptions are not entirely comparable (Adler, 1976; Broström, 1966; Freeman et al, 1965; Van Moppes and Van den Hoogenband, 1982).

Although the differences between the two treatments are not statistically significant with regard to the overall results it can be stated that 1) the mobile Pliton- 80 bandage is subjectively more acceptable to the patients, 2) the time off work in the Pliton-80 group is considerably shorter and 3) the residual symptoms at the 6 months follow-up do not differ significantly in the two treatment groups. Additionally the shorter sick-leave combined with a noted lower frequency of split repairs in the Pliton-80 group offers economical benefits.

With respect to the very large number of patients seen in the emergency department with this particular injury we find sufficient reason to recommend the mobile Pliton- 80 bandage as the treatment of ruptures to the fibular ankle ligaments.

\section{REFERENCES}

Adler, H., 1976 “Therapie und Prognose der frischen Aussenknöchel-bandläsion". Unfallheilkunde 79: 101-104.

Armitage, P., 1977. Statistical Methods in Medical Research. 4th Edition, Oxford, Edinburgh: Blackwell Scientific.

Brand, R. L., 1977 “The natural history of inadequately treated ankle sprain". Am.J.Sports Med. 5 (6): 248-249.

Broström, L., 1966 "Sprained ankles. Treatment and prognosis in recent ligament ruptures". Acta Chir.Scand. 132: 537-550.

Cetti, R., 1981 "Conservative treatment of injury to the fibular ligaments of the ankle". Brit.J.Sports Med. 16: 47-52.

Clark, B. L., Derby, A. C. and Power, G. R. J., 1965 "Injuries of the lateral ligament of the ankle. Conservative vs operative repair". Can.J.Surg. 8: 358-363.

Evans, G. S. and Frenyo, S. D., 1979 "The stress tenogram in the diagnosis of ruptures of the lateral ligament of the ankle". J.Bone Jt.Surg.(Br.) 61B: 347-351.

Freeman, M. A. R., Dean, M. R. E. and Hanham, I. W. D., 1965 "The etiology and prevention of functional instability of the foot". J.Bone Jt.Surg. (Br.) 47B: 678-685. 
Freeman, M. A. R. 1965 "Treatment of ruptures of the lateral ligament of the ankle". J.Bone Jt.Surg.(Br.) 47B: 661-OD 668. Glasgow, M., Jackson, A. and Jamieson, A. M., 1980 "Instability of the ankle after injury to the lateral ligament".
J.Bone Jt.Surg.(Br.) 62B: 196-200.

Niedermann, B., Andersen, A., Bryde-Andersen, S., Funder, V., Jørgensen, J. P., Lindholmer, E. and Vuust, M., 1981

"Rupture of the lateral ligaments of the ankle: Operation or plaster cast?" Acta Orthop.Scand. 52: 579-587.

Saunders, E. A., 1980 "Ligamentous injuries of the ankle". Practical Therapeutics 22 (2): 132-138.

Van Moppes, F. i. and Van den Hoogenband, C. R., 1982 “Diagnostic and therapeutic aspects of inversion trauma» to the ankle joint". Thesis, Maastricht.

Weber, B. G. and Hupfauer, W., 1969 "Zur Behandlung der frischen fibularen Bandruptur und der chronischen $\overrightarrow{\vec{\omega}}$ fibularen Bandinsuffizienz". Arch.Orthop.Unfallchir. 65: 251-257.

\section{BOOK REVIEW}

Title:

THE SPORTING WOMAN

Authors:

Mary A. Boutilier and Lucinda San Giovanni

Publishers:

Human Kinetics per Eddington Hook, Tonbridge, Kent

Price: $£ 17.60$ or $\$ 26.25$

The Sporting Woman is a text that can be used to provide factual information about the Sporting Woman in the USA a standard sense. Equally it could be used by students and lecturers, who wish to make comparative studies of either Sporting Woman in for example Great Britain and the USA or a comparison of men's and women's participation in sports, as a working manual providing a framework for study and further research.

The authors have given a broad brush approach, to the topic, supplemented by detailed analyses, questions, explor- 3 ations of assumptions, supporting notes, models and further references and therefore a great deal of data is contained $\supset$ in the 286 pages.

The book is divided into 2 main parts: Central theoretical, methodological and disciplinary issues and institutional analyses. The 3 themes of growth in participation, scientific study of sport and feminist initiated evaluations and:women's place in sport have been combined in a social science perspective. The multifaceted nature of feminism 3 . provides the central framework for the book in which normative and non-normative approaches to sport have been defined.

The concept, "Sport and its values are a microcosm of the society itself", is explored in the context of a patriarchal institution. The premise that sport is a masculine domain and therefore, ". . sports (were) invented by men for men" leads to the inevitable conclusion that male domination, in sport, is the norm and this initial stance has influenced subsequent developments. The authors exploit the themes of tradition, expectations, the impact of the family as the $O$ foundation for the socialising process, the educational environment and role behaviour to reinforce the 'men's world' $N$ perspective which is reflected in Government public policy.

They have provided women's participation in the Olympic Games as a case study. The three objectives of reviewing the development and modernisation of sport, setting down a brief history of the sporting activity of women and $\tilde{\Phi}_{\bar{D}}$ detailing the recent explosion of female athletic activity have been achieved.

This book will make a welcome addition to Sport Literature and it should become a well thumbed text.

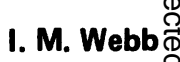

